Federal Reserve Bank of Dallas

Globalization and Monetary Policy Institute

Working Paper No. 41

http://www.dallasfed.org/assets/documents/institute/wpapers/2010/0041.pdf

\title{
Limited Asset Market Participation and the Consumption-Real Exchange Rate Anomaly ${ }^{*}$
}

\author{
Robert Kollmann \\ ECARES, Université Libre de Bruxelles and CEPR
}

January 2010

\begin{abstract}
Under efficient consumption risk sharing, as assumed in standard international business cycle models, a country's aggregate consumption rises relative to foreign consumption, when the country's real exchange rate depreciates. Yet, empirically, relative consumption and the real exchange rate are essentially uncorrelated. I show that this 'consumption-real exchange rate anomaly' can be explained by a simple model in which a subset of households trade in complete financial markets, while the remaining households lead hand-to-mouth (HTM) lives. HTM behavior also generates greater volatility of the real exchange rate and of net exports, which likewise brings the model closer to the data.
\end{abstract}

JEL codes: F41, F36, F47, F37, G15

\footnotetext{
* Robert Kollmann, ECARES; Université Libre de Bruxelles, 50 Av. Franklin Roosevelt, CP 114, B-1050 Brussels, Belgium. (32-2) 650-30-75. robert kollmann@yahoo.com. I thank Mick Devereux and Simona Cociuba for very helpful discussions. Useful comments were also received from Parantap Basu, Giancarlo Corsetti, Michael Evers, Gernot Müller, Dennis Novy, Paulo Santos Monteiro, Pedro Teles, Cédric Tille, and from workshop participants at EUI, IHEID (Geneva), Warwick, Bank of Greece (European Monetary Forum Conference), Konstanz Seminar, the Federal Reserve Board, and at the Dallas Fed-Bank of Canada Conference 'Capital Flows, International Financial Markets and Financial Crises.' Financial support from the National Bank of Belgium and the EU Commission is gratefully acknowledged. The views in this paper are those of the author and do not necessarily reflect the views of the Federal Reserve Bank of Dallas or the Federal Reserve System.
} 


\section{Introduction}

There is overwhelming evidence that consumption risk is not efficiently shared across countries. Under unrestricted trading in complete financial markets (as assumed in standard international business cycle models; e.g. Backus, Kehoe and Kydland (1994)), the real exchange rate is proportional to the ratio of domestic to foreign marginal utilities of consumption. This implies that, under optimal consumption risk sharing, a country's relative consumption rises, when its real exchange rate depreciates. That prediction holds regardless of frictions in goods markets (transportation costs, non-tradables, sticky prices etc). Yet, empirically, relative consumption and the real exchange rate are essentially uncorrelated (e.g., Backus and Smith (1993), Kollmann (1991, 1995)). Limited international risk sharing, as reflected in that 'consumption-real exchange rate anomaly', is one of the major puzzles in international macroeconomics; the solution of this puzzle would shed light on the functioning of international markets, with key potential implications for macro theory and policy (Obstfeld and Rogoff (2000), Obstfeld (2007)). ${ }^{1}$

Past attempts to explain the consumption-real exchange rate anomaly have mostly focused on models in which only a restricted set of assets can be traded internationally, while assuming that each country is inhabited by a representative agent, thus postulating efficient within-country hedging of risks; see, e.g. Obstfeld and Rogoff (1996), Heathcote and Perri (2002), Kollmann (1991, 1996). These modeling efforts have only had limited success. Even in structures in which just a riskless bond can be traded internationally, the national representative agents can typically achieve a surprising amount of cross-country risk pooling (by borrowing abroad when domestic output is low); as under complete markets, relative consumption rises thus whenever the real exchange rate depreciates. See e.g. Chari, Kehoe and McGrattan (2002) who conclude (based on the detailed analysis of a rich two-country DSGE model) that 'the most widely used forms of asset market incompleteness do not eliminate - or even shrink - the anomaly’ (p.561). ${ }^{2}$ Standard

\footnotetext{
${ }^{1}$ For empirical and theoretical discussions of this anomaly, see also i.a. Obstfeld (1993), Canova and Ravn (1996), Opazo (2006), Hoffmann (2004), Hadzi-Vaskov (2008), Devereux and Hnatkovska (2009), Coeurdacier, Kollmann and Martin (2008, 2009) and other papers cited below.

${ }^{2}$ Recently, Benigno and Thoenissen (2008) and Corsetti, Dedola and Leduc (2008) identified conditions (strong complementarities between domestic and foreign tradables, or highly volatile/persistent tradables supply shocks without foreign spillovers) under which a two-country model with just one traded bond can generate realistic (low) correlations between relative consumption and the real exchange rate. However, Benigno \& Küçük-Tuger (2009) show that these results are not robust to the introduction of a second traded asset; e.g. with trade in two
} 
incomplete markets models also seem problematic because, in reality, there is large-scale international trade in a wide array of assets (bonds, equities, derivatives); furthermore, consumption risk sharing is not only limited across countries, but also among the residents of the same country (e.g. Santos Monteiro (2008)).

In this paper, I show that the consumption-real exchange rate anomaly can be explained by a simple model in which only a subset of households trade freely in complete international financial markets; the remaining households do not participate in asset markets, and just consume their current labor income, thus leading 'hand-to-mouth' (HTM) lives. This ‘limited participation’ set-up provides a very transparent integration of within-country heterogeneity, into a model of the world economy. The results here suggest that the consumption-real exchange rate anomaly might not be due to the underdevelopment of international financial markets, but to the fact that a significant fraction of agents does not participate in those markets. Empirically, few households have foreign assets/liabilities (e.g. Christelis and Georgarakos (2009)).

The HTM behavior assumed here can reflect household myopia, or simple ruleof-thumb decision making (Mankiw (2000)). Empirically, a sizable fraction of households holds zero financial assets (Haliassos (2006)), and aggregate consumption growth closely tracks income growth (Carroll and Summers (1989)). The closed economy literature has argued that the presence of HTM households may explain these facts (Campbell and Mankiw (1989)); that literature has also suggested that HTM households may rationalize the macroeconomic effects of fiscal policy (Galì, Lopez-Salido and Vallés (2007)), and the equity premium (Weil (1990)). By contrast, the HTM assumption has received little attention in the open economy macro literature, with the notable exception of Devereux, Smith and Yetman (2009). ${ }^{3}$

nominal bonds, the Benigno-Thoenissen model again predicts that relative consumption changes are almost perfectly correlated with the rate of real exchange rate depreciation (as under complete markets).

Another drawback of standard incomplete markets models is that they predict that the expected growth of relative consumption is perfectly correlated with the expected rate of real exchange rate depreciation (this follows from agents' Euler equations if at least one asset is traded by all agents, as assumed in these models). That prediction holds even if the unconditional consumption-real exchange rate correlation is close to zero. Using survey data, Engel and Rogers (2008) and Devereux, Smith and Yetman (2009) show that expected growth rates of relative consumptions and real exchange rates are uncorrelated.

${ }^{3}$ Using a model that differs from the present structure, Devereux et al. argue that the presence of HTM agents can explain why, in the data, expected changes in relative consumption are 
The model here assumes a two-country world; each country produces a different tradable good, and uses domestic and foreign inputs for consumption and physical investment; there is a local bias in consumption and investment spending. There are country-specific shocks to output, to investment spending, and to the share of GDP received by HTM households.

In the HTM structure here, as in a structure with full risk sharing (no HTM households), shocks to output and investment individually induce negative co-movement between a country's relative aggregate consumption, and its real exchange rate, defined as the ratio of the country's CPI to the foreign CPI (expressed in common currency): in both structures, an exogenous increase in the output of country 'Home', say, raises Home (relative) consumption, and depreciates (lowers) the Home real exchange rate; a Home investment boom crowds out Home consumption and appreciates the real exchange rate (due to the local spending bias). With full risk sharing, relative consumption and the real exchange rate are perfectly negatively correlated, when there are simultaneous output and investment shocks. The presence of HTM households breaks that perfect negative correlation (under simultaneous shocks). For when there are HTM households, a positive shock to Home investment triggers a stronger real exchange rate appreciation, and a more muted fall in Home relative consumption, than under full risk sharing. Intuitively, the presence of HTM households lowers the price elasticity of relative world demand for Home (vs. Foreign) goods, as Home HTM households experience a positive income effect when the Home terms of trade improve (as Home consumption is biased towards the Home good, this income effect counteracts the negative substitution effect of the terms of trade change). With HTM households, a stronger terms of trade (and real exchange rate) adjustment is thus needed to clear the goods market, in response to investment shocks (and there is weaker crowding out of domestic consumption). On top of that, the model here assumes shocks to the share of GDP received by the HTM households (as mentioned above); those shocks are a source of positive co-movement between relative consumption and the real exchange rate.

uncorrelated with expected real exchange rate changes (see earlier footnote). The paper here was written simultaneously and independently of that study; it analyzes the effect of HTM agents on a broader set of macro facts, and provides more detailed analytical and numerical results.

Some large multi-country policy models assume HTM agents, mainly to match empirical responses to fiscal shocks (Erceg, Guerrieri and Gust (2006), Ratto, Roeger and in't Veld (2008), Forni and Pisani (2009)), but the role of the HTM feature for international risk sharing has not yet been analyzed using these models. 
I calibrate the model to data for the US and an aggregate of the remaining G7 countries. The baseline calibration assumes that HTM consumption accounts for $50 \%$ of total consumption, on average, which is in the range of empirical estimates of that share (Mankiw (2000)). The baseline HTM model predicts that a country's relative consumption is, essentially, uncorrelated with its real exchange rate, as is consistent with the data. In addition, the presence of HTM agents increases the volatility of the real exchange rate and of net exports, and it lowers the predicted cross-country correlation of consumption (compared to a setting without HTM households). This too brings the model closer to the data.

\section{The model}

\subsection{Preferences, endowments and markets}

There are two ex-ante symmetric countries, Home $(\mathrm{H})$ and Foreign $(\mathrm{F})$. Country $i=\mathrm{H}, \mathrm{F}$ produces $Y_{i}$ units of a traded good $i$. Country $i$ is inhabited by two households. The first agent is a hand-to-mouth household, HTM, who receives an exogenous fraction $\lambda_{i}$ of local output, $Y_{i}$. The second household receives $\left(1-\lambda_{i}\right) Y_{i}$, and she trades in a complete financial market, with her foreign counterpart; I refer to her as a 'risk sharer', RS. The Home and Foreign RS households also finance real investment spending. The HTM and RS households can be interpreted as a worker, and as an entrepreneur, respectively. Household $h=\mathrm{HTM}$, RS in country $i$ has the utility function $U\left(C_{i}^{h}\right)=\frac{1}{1-\sigma}\left\{\left(C_{i}^{h}\right)^{\sigma-1}-1\right\}$, where $C_{i}^{h}$ is real consumption, a composite of local and imported inputs:

$$
C_{i}^{h}=\left[\alpha^{1 / \phi}\left(c_{i}^{i, h}\right)^{(\phi-1) / \phi}+(1-\alpha)^{1 / \phi}\left(c_{i}^{j, h}\right)^{(\phi-1) / \phi}\right]^{\phi /(\phi-1)}, j \neq i
$$

$c_{i}^{j, h}$ is the household's consumption of good $j . \sigma>0$ and $\phi>0$ are the risk aversion coefficient, and the substitution elasticity between goods. There is a preference bias for the local good: $1 / 2<\alpha<1$. The welfare based CPI is $P_{i} \equiv\left[\alpha\left(p_{i}\right)^{1-\phi}+(1-\alpha)\left(p_{j}\right)^{(1-\phi)}\right]^{1 /(1-\phi)}$, where $p_{i}$ is the price of good $i$.

The Home terms of trade and real exchange rate are defined as $q \equiv p_{H} / p_{F}$ and $R E R \equiv P_{H} / P_{F}$, respectively. (Note that an increase in $R E R$ is an appreciation of the Home real exchange rate.)

The real consumption of the HTM household is: 


$$
C_{i}^{H T M}=p_{i} \lambda_{i} Y_{i} / P_{i} .
$$

Efficient risk sharing between Home and Foreign RS households implies that the ratio of their marginal utilities of consumption is equated to the real exchange rate (Kollmann (1991, 1995), Backus and Smith (1993)):

$$
\left(C_{H}^{R S}\right)^{-\sigma} /\left(C_{F}^{R S}\right)^{-\sigma}=R E R .
$$

This implies that (up to a linear approximation) the relative consumption of the Home (vs. Foreign) RS household, $C_{H}^{R S} / C_{F}^{R S}$, is perfectly negatively correlated with the Home real exchange rate.

Real investment in country $i$, denoted by $I_{i}$, is a composite good that has the same structure as aggregate consumption (1). Spending is allocated to inputs $\mathrm{H}$ and F so that marginal rates of substitution between these goods are equated to their relative price. Thus:

$$
c_{i}^{i, h}=\alpha\left(p_{i} / P_{i}\right)^{-\phi} C_{i}^{h}, c_{i}^{j, h}=(1-\alpha)\left(p_{j} / P_{i}\right)^{-\phi} C_{i}^{h}, t_{i}^{i}=\alpha\left(p_{i} / P_{i}\right)^{-\phi} I_{i}, t_{i}^{j}=(1-\alpha)\left(p_{j} / P_{i}\right)^{-\phi} I_{i} \quad(j \neq i),
$$

for $i, j=H, F$ and $h=H T M, R S$ where $u_{i}^{j}$ is country $i$ investment demand for good $j$. Market clearing requires: $\sum_{j=H, F}\left\{c_{j}^{i, H T M}+c_{j}^{i, R S}+l_{j}^{i}\right\}=Y_{i}$ for $i=H, F$.

The above equations pin down consumptions and the terms of trade, given output, investment and the HTM share of GDP, in the two countries $\left(Y_{i}, I_{i}, \lambda_{i}\right.$ for $\left.i=H, F\right)$. Here, I do not endogenize $Y_{i}, I_{i}, \lambda_{i}$. The focus is on the behavior of consumption and the real exchange rate, conditional on these forcing variables. I set the second moments of the forcing variables equal to observed second moments for the US and an aggregate of the remaining G7 countries. ${ }^{4}$ I normalize $E Y_{i}=1$ and denote mean investment and the mean HTM share of GDP by $\Xi \equiv E I_{i}>0$ and $\Lambda \equiv E \lambda_{i}$, respectively, with $0<\Lambda+\Xi<1$.

\footnotetext{
${ }^{4}$ The working paper version of this paper (Kollmann (2009)) presents a dynamic HTM model with endogenous production and investment. Like the static model here, that dynamic model explains the consumption-real exchange rate anomaly. If a dynamic model (with the same preferences as the static model here) reproduces the empirical moments of $Y_{i}, I_{i}, \lambda_{i}$ (that are calibrated in the static model), then the dynamic model generates the same consumption-real exchange rate correlation as the static model.
} 


\subsection{Model solution}

I linearize the model around mean values of the forcing variables. $\hat{z} \equiv(\mathrm{z}-\overline{\mathrm{z}}) / \bar{z}$ is the relative deviation of variable $z$ from the point of linearization, $\bar{z}$. The following variables without subscripts represent ratios of Home to Foreign variables: $C^{H T M} \equiv C_{H}^{H T M} / C_{F}^{H T M}$, $C^{R S} \equiv C_{H}^{R S} / C_{F}^{R S}, \quad I \equiv I_{H} / I_{F}, \quad Y \equiv Y_{H} / Y_{F}, \lambda \equiv \lambda_{H} / \lambda_{F}$.

The real exchange rate obeys: $\widehat{R E R}=(2 \alpha-1) \hat{q}$; a Home terms of trade improvement induces thus a real exchange rate appreciation (due to the local spending bias, $\alpha>0.5$ ).

(2) implies that the relative (Home/Foreign) consumption of HTM households is:

$$
\widehat{C^{H T M}}=\widehat{Y}+\widehat{\lambda}+2(1-\alpha) \hat{q} .
$$

An increase in (relative) Home GDP and in the fraction of GPD received by the Home HTM household, and a Home terms of trade improvement all raise the relative consumption of the Home (vs. Foreign) HTM household. By contrast, the relative (Home/Foreign) consumption of RS households is a decreasing function of the terms of trade, as (3) implies:

$$
\widehat{C^{R S}}=-\frac{1}{\sigma}(2 \alpha-1) \hat{q} \text {. }
$$

From (4), relative world demand for good $\mathrm{H}$ (relative to demand for good F) obeys:

$$
d \equiv \frac{c_{H}^{H, H T M}+c_{H}^{H, R S}+l_{H}^{H}+c_{F}^{H, H T M}+c_{F}^{H, R S}+l_{F}^{H}}{c_{H}^{F, H T M}+c_{H}^{F, R S}+l_{H}^{F}+c_{F}^{F, H T M}+c_{F}^{F, R S}+l_{F}^{F}}=q^{-\phi} \frac{\alpha R E R^{\phi} A+1-\alpha}{\alpha+(1-\alpha) R E R^{\phi} A},
$$

with $A \equiv A_{H} / A_{F}$ where $A_{i} \equiv C_{i}^{H T M}+C_{i}^{R S}+I_{i}$ is absorption in country $i$. This implies:

$$
\hat{d}=-\phi \hat{q}+(2 \alpha-1)(\phi \widehat{R E R}+\hat{A})=-4 \alpha(1-\alpha) \phi \hat{q}+(2 \alpha-1) \hat{A} .
$$

Using (5)-(7), relative demand can be expressed as:

$$
\hat{d}=-\Gamma \hat{q}+(2 \alpha-1) \Lambda(\hat{\lambda}+\hat{Y})+(2 \alpha-1) \Xi \hat{I},
$$

where $\Gamma \equiv 4 \alpha(1-\alpha) \phi+(1-2 \alpha)^{2}(1-\Lambda-\Xi) / \sigma-2(2 \alpha-1)(1-\alpha) \Lambda$ is the elasticity of relative world demand for the Home traded good with respect to the Home terms of trade, q. (To get (7),(8), I use $\bar{A}=\overline{R E R}=1$, due to symmetry, and $\widehat{A}=\Lambda \widehat{C^{H T M}}+(1-\Lambda-\Xi) \widehat{C^{R S}}+\Xi \hat{I}$.)

$\Gamma>0$ holds under full risk sharing, i.e. when there are no HTM households $(\Lambda=0)$. $\Gamma$ is decreasing in $\Lambda$, the mean share of GDP received by HTM households. The presence of HTM households lowers thus the price elasticity of relative demand. 
Intuitively, an improvement of the Home terms of trade raises the relative income of the Home HTM household; as Home consumption spending is biased towards the Home good, this income effect counteracts the negative substitution effect of the terms of trade improvement on the relative world demand for good $\mathrm{H}$. The income effect of a terms of trade improvement is stronger, the greater is $\Lambda$, which explains why $\partial \Gamma / \partial \Lambda<0$. However, $\Gamma>0$ holds for plausible values of $\Lambda$ (see Appendix). The following discussions thus assume $\Gamma>0$.

Market clearing requires that relative demand equals relative output: $d=Y$. A rise in Home relative output $Y$ triggers a deterioration of the equilibrium Home terms of trade: at unchanged terms of trade, a 1\% increase in $Y$ raises relative demand for good $\mathrm{H}$ by less than $1 \%$, namely by $(2 \alpha-1) \Lambda \%$ (see (8)); market clearing thus requires a fall of the relative price of good $H$ (provided $\Gamma>0$ ). (8) shows that increases in Home relative real investment spending $(I)$ and the relative share of GDP received by Home (vs. Foreign) HTM households $(\lambda)$ both raise the relative demand for good H; those shocks trigger thus an equilibrium improvement of the Home terms of trade and an appreciation of the Home real exchange rate. Hence (see Appendix):

$$
\widehat{R E R}=a_{Y} \hat{Y}+a_{I} \hat{I}+a_{\lambda} \hat{\lambda}
$$

$$
(-) \quad(+) \quad(+)
$$

Relative 'national' consumption $C \equiv C_{H} / C_{F}$, with $C_{i} \equiv C_{i}^{H T M}+C_{i}^{R S}(i=H, F)$ obeys:

$$
\widehat{C}=b_{Y} \hat{Y}+b_{I} \hat{I}+b_{\lambda} \hat{\lambda} \text {. }
$$

$(+) \quad(-) \quad(+)$

An increase in Home relative output $Y$ raises Home relative consumption $C$, while a rise in relative investment $I$ lowers $C$, for plausible parameter values (see Appendix). As an increase in $\lambda$ improves the Home terms of trade, it is accompanied by an increase in Home relative consumption. ${ }^{5}$

When there are no HTM households $(\Lambda=0)$, relative consumption is perfectly negatively correlated with the real exchange rate, and thus $a_{Y} / a_{I}=b_{Y} / b_{I}<0$. In the calibrated model (see below) an increase in the expected share of GDP received by the

\footnotetext{
5 (7) and $Y=d$ imply that any shock that improves the Home terms of trade, at unchanged Home relative output, has to be associated with a rise in Home relative absorption $A$. Thus, an increase in $\lambda$ (for given $Y, I$ ) raises $C$.
} 
HTM households $(\Lambda)$ has a weak effect on $a_{Y}, b_{Y}$ (for plausible parameter values, $a_{Y}, b_{Y}$ can be increasing or decreasing in $\Lambda$ ). A rise in Home investment improves the Home terms of trade more strongly, the greater is $\Lambda$ (as the price elasticity of relative world demand for good $\mathrm{H}$ is decreasing in $\Lambda$ ). Due to the positive income effect received by the Home HTM household, when the Home terms of trade improve, Home relative consumption falls less strongly in response to a Home investment shock, the greater is $\Lambda$. Thus the response coefficients $a_{I}, b_{I}$ (see (9), (10)) are increasing in $\Lambda$. This mechanism, due to the presence of HTM households, breaks the perfect negative correlation between relative consumption and the real exchange rate, when the economy is simultaneously subjected to output and investment shocks. A $1 \%$ rise in the relative GDP share of the Home/Foreign HTM agent $(\lambda)$ appreciates the Home real exchange rate and raises Home relative consumption more strongly, the greater is $\Lambda$ (i.e. $a_{\lambda}$ and $b_{\lambda}$ are increasing functions of $\Lambda$; see Appendix).

\subsection{Model calibration}

Following Kollmann (2004), I calibrate the model to data for the US and an aggregate of the remaining G7 countries, referred to as the 'G6'. ${ }^{6}$ All data are annual and (unless stated otherwise) cover 1972-2003.

\section{Preference parameters, investment and HTM income shares}

US exports [imports] to/from the G6 amounted to 3.10\% [4.64\%] of US GDP and 2.44\% [3.71\%] of G6 GDP, on average during 1980-2003. ${ }^{7}$ Thus, the average US-G6 trade share was about 3.5\%. Hence, I set the local spending share parameter at $\alpha=0.965$. Across G7 countries, the mean investment/GDP ratio is $22 \%$; I thus set $\Xi=0.22$. $\phi$ corresponds to the price elasticity of imports and exports. In macro models, $\phi$ is typically set at values roughly between 1 and 2. Hooper and Marquez (1995) survey a large number of econometric estimates of $\phi$, based on aggregate trade flows, for the US, Japan, Germany, UK and Canada; the median estimates (post-Bretton Woods) for these countries are 0.97,

\footnotetext{
${ }^{6} \mathrm{G} 6$ variables are geometric weighted averages of individual countries' data (weights: mean shares in G6 GDP).

${ }^{7}$ From IMF Directions of Trade Statistics electronic database (that reports bilateral trade flows starting in 1980).
} 
$0.80,0.57,0.60$ and 1.01, respectively; the median estimate across all 5 countries is 0.9 . In the baseline calibration, I thus set $\phi=0.9$, but I also report results for $\phi=2$. Estimates of the risk aversion coefficient $(\sigma)$ in the range of 2 or greater are common for industrialized countries (Barrionuevo (1992)); the baseline calibration uses $\sigma=2$.

The baseline calibration assumes that, on average, 50\% of total consumption accrues to HTM households; this implies that HTM consumption represents a fraction $\Lambda=0.39\left(=0.5^{*}(1-\Xi)\right)$ of GDP, on average. This is in the range of estimated income share of HTM consumers, for the US and other industrialized countries; e.g., Campbell and Mankiw (1989, 1990, 1991) and Mankiw (2000).

\section{Stochastic properties of the forcing variables}

Empirically, participation in financial markets is highly positively correlated with household wealth; households whose main source of income is labor income are much less likely to hold internationally traded assets (e.g. Christelis and Georgarakos (2009)). I thus take fluctuations in a country's labor share (fraction of GDP received by labor) as a proxy for movements in the fraction of GDP received by the local HTM household, $\lambda_{i}$.

US and G6 GDP, investment and labor shares undergo persistent fluctuations. I use the second moments of (annual) growth rates of these series (1972-2003), to calibrate the second moments of the model's forcing variables. ${ }^{8}$ The standard deviations of growth rates of relative US/G6 GDP, investment and labor shares are 1.70\%, 7.69\% and 1.41\%, respectively; relative investment is thus more volatile than relative output; the relative labor share is less volatile. The correlation between relative US/G6 GDP and investment growth is 0.86; relative labor share growth is only weakly correlated with relative output growth (0.09) and relative investment growth (-0.16). In the simulations, I thus set the second order moments of the relative forcing variables $\hat{Y}, \hat{I}, \hat{\lambda}$ at:

$$
\begin{gathered}
\operatorname{std}(\hat{Y})=1.70 \%, \operatorname{std}(\hat{I})=7.69 \%, \operatorname{std}(\hat{\lambda})=1.41 \%, \\
\operatorname{Corr}(\hat{Y}, \hat{I})=0.86, \operatorname{Cor}(\hat{Y}, \hat{\lambda})=0.09, \operatorname{Cor}(\hat{I}, \hat{\lambda})=-0.16
\end{gathered}
$$

\footnotetext{
${ }^{8}$ Source of all data (unless stated otherwise): International Financial Statistics, OECD National Accounts. The empirical measure of the labor share is (compensation of employees)/(GDPindirect taxes).
} 
I set the moments of $\hat{Y}_{i}, \hat{I}_{i}, \hat{\lambda}_{i}$ in countries $i=H, F$ at averages (across US, G6) of the corresponding empirical statistics. This gives: $\operatorname{std}\left(\widehat{Y}_{i}\right)=1.76 \%, \operatorname{std}\left(\widehat{I}_{i}\right)=6.84 \%, \operatorname{std}\left(\widehat{\lambda}_{i}\right)=1.04 \%$, $\operatorname{Corr}\left(\widehat{Y}_{i}, \widehat{I}_{i}\right)=0.90, \operatorname{Corr}\left(\widehat{Y}_{i}, \widehat{\lambda}_{i}\right)=-0.26, \operatorname{Corr}\left(\widehat{I}_{i}, \widehat{\lambda}_{i}\right)=-0.36$. Thus, investment in each country is more volatile than output or the labor share. Investment is strongly procyclical, while the labor share is countercyclical. ${ }^{9}$

\section{Consumption and the real exchange rate: facts and model predictions}

\subsection{Empirical statistics}

The empirical correlation between (growth rates of) relative US/G6 consumption of nondurables and services, and the real exchange rate is 0.24 (with a standard error of 0.13 ). For other individual G7 countries (compared to corresponding rest-of-G7 aggregates), the correlation between relative consumption and the real exchange rate (in growth rates) ranges between -0.18 (Japan) and 0.12 (Germany); the mean correlation is 0.03 . The Table below reports mean values, across the US and G6, of other empirical statistics (see Col. (5)). All statistics pertain to annual growth rates (exception: the statistic for (bilateral) net exports, normalized by GDP, refers to first-differenced series). The US-G6 real exchange rate (standard deviation: 8.25\%) is more volatile than output. Consumption and net exports (standard deviations: 1.06\%, 0.29\%) are less volatile than output (1.76\%). In the data, consumption is highly positively correlated with domestic output (correlation: 0.71). However, consumption is only weakly correlated across the US and the G6 (0.19).

\subsection{Model predictions}

The Table also reports moments generated by the model; Columns (1)-(3) pertain to the HTM structure (Col. (1) assumes all three types of shocks; Col. (2) assumes just output and investment shocks, while Col. (3) assumes just shocks to output and to HTM income shares). Col. (4) assumes full risk sharing (no HTM households, $\Lambda=0$ ), with output and investment shocks.

\footnotetext{
${ }^{9}$ The (symmetrized) cross-country correlations are: $\operatorname{Corr}\left(\widehat{Y}_{i}, \widehat{Y}_{j}\right)=.53, \operatorname{Corr}\left(\widehat{I}_{i}, \widehat{I}_{j}\right)=.36, \operatorname{Corr}\left(\widehat{\lambda}_{i}, \widehat{\lambda_{j}}\right)=.09$, $\operatorname{Corr}\left(\widehat{Y}_{i}, \widehat{I}_{j}\right)=.42, \operatorname{Corr}\left(\widehat{Y}_{i}, \widehat{\lambda}_{j}\right)=-.34, \operatorname{Corr}\left(\hat{I}_{i}, \widehat{\lambda}_{j}\right)=-.24$ for $i \neq j$.
} 


\subsubsection{Baseline calibration}

Under the baseline calibration of the HTM model, the real exchange rate and relative consumption obey:

$$
\widehat{R E R}=-2.23 \hat{Y}+0.71 \hat{I}+1.24 \hat{\lambda}, \quad \widehat{C}=0.97 \hat{Y}-0.15 \hat{I}+0.23 \hat{\lambda} .
$$

By contrast, with full risk sharing (no HTM households):

$$
\widehat{R E R}=-2.02 \hat{Y}+0.40 \hat{I}, \quad \widehat{C}=1.01 \hat{Y}-0.20 \hat{I} .
$$

Note that, in both structures, shocks to relative output and investment $(Y, I)$ drive $R E R$ and $C$ in opposite directions. Under full risk sharing $a_{Y} / b_{Y}=a_{I} / b_{I}<0$ holds (as discussed above). In the baseline structure with HTM households the Home real exchange appreciates $77 \%$ more strongly than under full risk sharing, in response to a given rise in Home relative investment, while the drop of Home relative consumption is $25 \%$ weaker; this breaks the perfect negative correlation between $\widehat{R E R}$ and $\widehat{C}$, when there are simultaneous output and investment shocks. On top of that, in the baseline HTM structure, a $1 \%$ increase in $\lambda$ (relative Home/Foreign HTM GDP share) appreciates the Home real exchange rate by $1.24 \%$ and it raises Home relative consumption by $0.23 \%$.

As reported in Panel (a) of the Table, the baseline HTM model predicts that the correlation between (relative) consumption and the real exchange rate is -0.07 , with all shocks (see Col. (1)). Thus, relative consumption is predicted to be essentially uncorrelated with the real exchange rate. With just output and investment shocks, the predicted $C$-RER correlation is -0.39 (see Col. (2)); hence, even when there are no $\lambda$-shocks, the HTM-model generates a $C$-RER correlation that is markedly above the correlation under complete markets $(-1.00)$. Consistent with the theoretical analysis above, the simultaneous presence of output and investment shocks is important for the ability of the HTM model to generate a realistic C-RER correlation: when the investment shock is eliminated, the correlation drops to -0.79 (see Col. (3)).

The predicted standard deviation of the real exchange rate is $2.69 \%$, in the baseline HTM structure (all shocks), compared to 1.74\% under full risk sharing. The real exchange rate is thus more volatile, in the presence of HTM households (see discussion above). Regarding the other predicted statistics reported in the Table, the main differences between the baseline HTM structure and the variant with full risk sharing are: (1.) In the baseline HTM structure, the standard deviation of net exports $(0.13 \%)$ is about 
twice as large as under full risk sharing (0.06\%), and thus closer to the empirical standard deviation (0.29\%). Home net exports obey $N X_{H}=\frac{1-\alpha}{2 \alpha-1}\left\{1-\frac{2 \alpha}{2 \alpha-1} \phi\right\} \widehat{R E R}-\frac{1-\alpha}{2 \alpha-1} \hat{Y}$; intuitively, $N X$ is more volatile in the HTM structure, due to the greater volatility of the real exchange rate. (2.) The cross-country consumption correlation is lower in the HTM structure, 0.40 (compared to 0.54 under full risk sharing) and thus likewise closer to the empirical correlation (0.19).

In the baseline HTM structure, the predicted standard deviation of consumption (0.96\%), and the correlation between domestic consumption and output (0.63) are likewise higher than under full risk sharing (corresponding statistics there: $0.91 \%$ and 0.57) — but here the difference between the two model structures is less strong; however, the presence of HTM households moves these predicted statistics closer to the empirical statistics (1.06\%, and 0.71).

\subsubsection{Model variant with a larger expected income share of HTM households $(\Lambda=0.6)$}

The predicted $C$-RER correlation is increasing in the expected share of HTM income in GDP, $\Lambda$. In Panel (b) of the Table, $\Lambda$ is set at a larger value than in the baseline calibration, namely at the average empirical labor share (in US and G6): $\Lambda=0.6$ (implied mean share of HTM consumption in total consumption: 77\%). Under that calibration, the predicted correlation between relative consumption and the real exchange rate (with all shocks) is 0.63 , which is greater than the empirical correlation (0.24); with just output and investment shocks, the predicted correlation between relative consumption and the real exchange rate remains sizable: 0.40 .

When $\Lambda=0.6$, the predicted standard deviation of the real exchange rate is $6.04 \%$ (with all shocks); predicted real exchange rate volatility is thus much closer to the empirical volatility (8.25\%) than under the baseline HTM calibration (2.69\%). ${ }^{10}$ The model variant with a high HTM income share also generates higher standard deviations of consumption $(1.11 \%)$ and net exports $(0.24 \%)$ than the baseline calibration--these predicted statistics too are closer to the empirical moments.

\footnotetext{
${ }^{10}$ For $\Lambda=0.6$, the real exchange rate is more sensitive to $I \& \lambda$ shocks (than in baseline calibration); relative consumption is less sensitive to $I$ shocks, but more sensitive to $\lambda$ shocks $\left(a_{I}=1.18, a_{\lambda}=3.23, b_{I}=-0.06, a_{\lambda}=0.58\right)$.
} 


\subsubsection{Model variant with lower expected income share of HTM households $(\Lambda=0.25)$}

Panel (c) of the Table reports results for a model variant with a lower expected share of HTM income in GDP: $\Lambda=0.25$ (implied mean share of HTM consumption in total consumption: 32\%). The predicted C-RER correlation generated by the HTM structure now is -0.61 (with all shocks) while the standard deviation of the real exchange rate is $1.92 \%$. Thus, the predicted C-RER correlation remains noticeably larger than under full risk sharing (-1.0). However, manifestly, a higher mean HTM income share is required to generate a realistic correlation between relative consumption and the real exchange rate.

\subsubsection{Variant with higher substitution elasticity between Home \& Foreign goods $(\phi=2)$}

Panel (d) reports results for a model variant with $\phi=2$, i.e. in which Home and Foreign tradables are more substitutable than in the baseline calibration. (NB $\Lambda$ is again set at its baseline value: $\Lambda=0.39$.) The HTM structure now generates a correlation between relative consumption and the real exchange rate of 0.12 , with all three types of shocks (and of -0.14 with just output and investment shocks). Thus, the predicted correlation is higher than under the baseline calibration, and closer to the empirical correlation (0.24).

The real exchange rate and relative consumption respond less strongly to output and investment shocks, when the two goods are closer substitutes. The predicted standard deviation of the real exchange rate is thus lower than in the baseline calibration; however the predicted standard deviation remains larger in the HTM structure (1.72\%) than under full risk sharing (1.32\%).

\subsubsection{Model variant with greater risk aversion $(\sigma=5)$}

Panel (e) shows results for a model variant in which the risk aversion coefficient is increased to $\sigma=5$ (all other parameters are set at baseline values). With the three types of shocks, the HTM structure now generates a predicted $C-R E R$ correlation of 0.20 , which is very close to the empirical correlation, 0.24 (with just output and investment shocks, the predicted correlation is -0.02 ). With greater risk aversion, relative world demand for the Home good is less sensitive to the terms of trade (as the relative consumption of Home/Foreign RS households responds less to the terms of trade, see (6)). Thus, the standard deviation of the real exchange rate (4.35\%) is noticeably higher (and closer to the empirical statistics) than under the baseline calibration. The predicted standard deviation of net export ( $0.17 \%)$ too is higher, and closer to the empirical statistic. 


\section{Conclusion}

This paper has argued that the presence of hand-to-mouth (HTM) households may help to solve a key puzzle in international macroeconomics - the fact that relative consumption and the real exchange rate are essentially uncorrelated. To match this fact, the model here requires that the share of HTM consumption in total consumption is about $50 \%$. The results suggest that the consumption-real exchange rate anomaly might not be due to the underdevelopment of international financial markets, but to the fact that a significant fraction of agents does not participate in those markets. Especially when agents are highly risk averse, the presence of HTM households also generates greater volatility of the real exchange and of net exports, which likewise brings the model closer to the data. 


\section{APPENDIX: Solutions for real exchange rate and relative national consumption}

The solutions for the Home real exchange rate and for Home relative consumption are:

$\widehat{R E R}=a_{Y} \hat{Y}+a_{I} \hat{I}+a_{\lambda} \hat{\lambda}$ with $a_{Y} \equiv\left[\Lambda(2 \alpha-1)^{2}+(1-2 \alpha)\right] \Gamma, a_{I} \equiv \Xi(2 \alpha-1)^{2} / \Gamma, a_{\lambda} \equiv \Lambda(2 \alpha-1)^{2} /(\sigma \Gamma)$,

and $\hat{C}=b_{Y} \hat{Y}+b_{I} \hat{I}+b_{\lambda} \hat{\lambda}$, with $b_{Y} \equiv \frac{1}{1-\Xi} \frac{1}{\sigma}[(1-\Lambda-\Xi)(2 \alpha-1)-\sigma \Lambda 2(1-\alpha)(1-2 \phi \alpha)] \Gamma$,

$b_{I} \equiv \frac{\Xi}{1-\Xi} \frac{1}{\sigma}\left[-(1-\Lambda-\Xi)(2 \alpha-1)^{2}+\sigma \Lambda 2(2 \alpha-1)(1-\alpha)\right] \Gamma, \quad b_{\lambda} \equiv \frac{\Lambda}{1-\Xi} 4 \alpha(1-\alpha) \phi / \Gamma$.

$\Gamma \equiv(1-2 \alpha)^{2}(1-\Lambda-\Xi) / \sigma-2(2 \alpha-1)(1-\alpha) \Lambda+4 \alpha(1-\alpha) \phi$ is the price elasticity of relative world demand for good $\mathrm{H}$. When $\Lambda=0$ (full risk sharing), then $\Gamma>0$. $\Gamma>0$ also holds when there are HTM households, if $\Lambda$ (mean share of HTM income in GDP) is not too big. Note that $\Gamma>0 \Leftrightarrow \Lambda<\frac{\phi \sigma 4 \alpha(1-\alpha) /(2 \alpha-1)+(1-\Xi)(2 \alpha-1)}{2(1-\alpha) \sigma+(2 \alpha-1)}$. The right-hand side of this inequality is positive. Assume the baseline parameter values $\alpha=0.965, \Xi=0.22, \phi=0.9, \sigma=2$; then $\Gamma>0$ holds for all feasible values of $\Lambda$ (i.e. for $0 \leq \Lambda<1-\Xi$ ). Alternatively, note that $\Gamma>0$ holds iff $\phi>\Lambda \frac{2 \alpha-1}{2 \alpha}-\frac{(1-2 \alpha)^{2}(1-\Lambda-\Xi)}{4 \alpha(1-\alpha) \sigma}$. The right-hand side of this inequality cannot exceed $0.5 \cdot(1-\Xi)$ (as $\alpha<1$ and $\Lambda<1-\Xi$ ); when $\Xi=0.22$, then a sufficient condition for $\Gamma>0$ is $\phi>0.39$. As discussed in the text, median estimates of $\phi$ based on aggregate trade data are mostly in the range of unity. Thus, $\Gamma>0$ is plausible. $\Gamma>0$ implies $a_{Y}<0, a_{I}>0$, and $a_{\lambda}>0, b_{\lambda}>0$ (when $\Lambda>0$ ).

An increase in Home relative output $(Y)$ raises relative consumption $\left(b_{Y}>0\right)$, for plausible parameter values: when $\Gamma>0$ holds, then $b_{\mathrm{Y}}>0$ obtains for $\phi>\frac{1}{2 \alpha}-\frac{1-\Lambda-\Xi}{\Lambda} \frac{1}{\sigma} \frac{2 \alpha-1}{4 \alpha(1-\alpha)}$. Assume the baseline values of $\alpha, \phi, \sigma, \Xi$. Then $b_{Y}>0$ holds for all $0 \leq \Lambda<1-\Xi$.

An increase in Home relative investment lowers relative consumption $\left(b_{I}<0\right)$ when $\Lambda<\frac{(1-\Xi)(2 \alpha-1)}{2(1-\alpha) \sigma+(2 \alpha-1)}$; under the baseline values of $\alpha, \Xi, \phi, \sigma$, we have $b_{I}<0$ when $\Lambda<0.677$.

Effect of changes in $\Lambda$ on real exchange rate and relative consumption responses to shocks At constant terms of trade, an increase in Home output creates an excess supply in the market for good $\mathrm{H}$; the greater is $\Lambda$, the smaller is that excess supply (a greater $\Lambda$ means that Home HTM household income rises more strongly in response to the increase in Home output, which raises demand for good $\mathrm{H}$ more strongly, and hence lowers the excess supply of good $\mathrm{H}$, at constant $q$ ). However, as an increase in $\Lambda$ also lowers the price elasticity $\Gamma$, its effect on the sensitivity of the real exchange rate to relative output $Y$ is ambiguous. $\partial a_{Y} / \partial \Lambda<0, \partial b_{Y} / \partial \Lambda<0$ hold iff $\sigma<\left[(2 \alpha-1)^{2} \Xi+2(2 \alpha-1)(1-\alpha)\right] /[2(1-\alpha)(2 \alpha \phi-1)]$. This condition is met when $\alpha$ is sufficiently close to unity.

As $\partial \Gamma / \partial \Lambda<0$, we see that $\partial a_{I} / \partial \Lambda, \partial b_{\mathrm{I}} / \partial \Lambda, \partial a_{\lambda} / \partial \Lambda, \partial b_{\lambda} / \partial \Lambda>0$. Thus, an increase in $I$ induces a stronger appreciation of the Home real exchange rate, but a weaker fall in Home relative consumption, the greater is $\Lambda$. An increase in $\lambda$ induces a stronger appreciation of the Home real exchange rate, and a stronger rise in Home relative consumption, the greater is $\Lambda$. 


\section{BIBLIOGRAPHY}

Backus, D., and G. Smith, 1993, Consumption and Real Exchange Rates in Dynamic Economies with Non-traded Goods, Journal of International Economics, 35, 297-316. Backus, D., P. Kehoe and F. Kydland, 1994, Dynamics of the Trade Balance and the Terms of Trade: the J-Curve? American Economic Review 84, 84-103

Barrionuevo, J., 1992, Asset Prices in the International Economy. Ph.D. Dissertation, University of Chicago.

Benigno, G. and H. Küçük-Tuger, 2008, Financial Globalization, Home Equity Bias and International Risk-Sharing, Working Paper, London School of Economics.

Benigno, G. and C. Thoenissen, 2008, Consumption and Real Exchange Rates With Incomplete Markets, Journal of International Money and Finance 27, 926-948.

Campbell, J. and G. Mankiw, 1989, Consumption, Income, and Interest Rates: Reinterpreting the Time Series Evidence, NBER Macro Annual 4, 185-216.

Campbell, J. and G. Mankiw, 1990, Permanent Income, Current Income and Consumption, Journal of Business \& Economic Statistics 8, 265-279.

Campbell, J. and G. Mankiw, 1991, The Response of Consumption to Income--A Cross Country Investigation, European Economic Review 35, 723-276.

Canova, F. and M. Ravn, 2006, International Consumption Risk Sharing, International Economic Review 37, 573-601.

Carroll, C. and L. Summers, 1989, Consumption Growth Parallels Income Growth: Some New Evidence, Working Paper 3090, National Bureau of Economic Research.

Chari, V., P. Kehoe and E. McGrattan, 2002, Can Sticky Price Models Generate Volatile and Persistent Real Exchange Rates? Review of Economic Studies 69, 533-563.

Christelis, D., D. Georgarakos, 2009, Investing at Home and Abroad: Different Costs, Different People? Working Paper, University of Frankfurt.

Coeurdacier, N., R. Kollmann and P. Martin, 2008, International Portfolios with Supply, Demand and Redistributive Shocks, NBER International Seminar on Macroeconomics 2007, 231-263.

Coeurdacier, N., R. Kollmann and P. Martin, 2009, International Portfolios, Capital Accumulation and Foreign Assets Dynamics, Journal of International Economics, forthcoming.

Corsetti, G., L. Dedola and S. Leduc, 2008, International Risk Sharing and the Transmission of Productivity Shocks, Review of Economic Studies 75, 443-473. 
Devereux, M. and V. Hnatkovska, 2009, International and Intra-national Real Exchange Rates: Theory and Evidence, Working Paper, University of British Columbia.

Devereux, M., G. Smith and J. Yetman, 2009, Consumption and Real Exchange Rates in Professional Forecasts, Queen’s Economics Department Working Paper 1195.

Engel, C. and J. Rogers, 2008, Expected Consumption Growth From Cross-Country Surveys, Working Paper, University of Wisconsin.

Erceg, C., L. Guerrieri and C. Gust, 2006, SIGMA: A New Open Economy Model for Policy Analysis, International Journal of Central Banking 2, 1-50.

Forni, L. and M. Pisani, 2009, Expansionary Fiscal Policy and the Trade Balance: Evidence from a Bayesian DSGE Model, Working Paper, Bank of Italy.

Galì, J., D. Lopez-Salido and J. Vallès, 2007, Understanding the Effects of Government Spending on Consumption, Journal of European Economic Association 5, 227-270.

Hadzi-Vaskov, M., 2008, Does the Nominal Exchange Rate Explain the Backus Smith Puzzle? Evidence from the Eurozone, DP 07-32, Tjalling Koopmans Institute.

Haliassos, M., 2006, Household Portfolios, Working Paper, University of Frankfurt.

Heathcote, J. and F. Perri, 2002, Financial Autarky and International Business Cycles, Journal of Monetary Economics 49, 601-27.

Hoffmann, M., 2004, International Prices and Consumption Risk Sharing, Working Paper, University of Dortmund.

Hooper, P. and J. Marquez, 1995, Exchange Rates, Prices, and External Adjustment in the United States and Japan, in: Kenen,-Peter, ed. Understanding Interdependence. Princeton: Princeton University Press, 1995, 107-68.

Kollmann, R., 1991, Essays on International Business Cycles, PhD Dissertation, Economics Department, University of Chicago.

Kollmann, R., 1995, Consumption, Real Exchange Rates and the Structure of International Asset Markets, Journal of International Money and Finance 14, 191-211. Kollmann, R., 1996, Incomplete Asset Markets and the Cross-Country Consumption Correlation Puzzle, Journal of Economic Dynamics and Control 20, 945-962.

Kollmann, R., 2004, Welfare Effects of a Monetary Union: the Role of Trade Openness, Journal of the European Economic Association 2, 289-301 
Kollmann, R., 2009, Domestic Financial Frictions: Implications for International Risk Sharing, Real Exchange Rate Volatility and International Business Cycles, Paper presented at the Fourth Workshop on Global Interdependence (CEPR), March 2009.

Mankiw, G., 2000, The Savers-Spenders Theory of Fiscal Policy, American Economic Review 90, 120-125.

Obstfeld, M., 1993, Are Industrial-Country Consumption Risks Globally Diversified? Working Paper 4308, National Bureau of Economic Research.

Obstfeld, M. and K. Rogoff, 1996, Foundations of International Macroeconomics, Cambridge, MA: MIT Press.

Obstfeld, M. and K. Rogoff, 2000, The Six Major Puzzles in International Macroeconomics: Is There a Common Cause? NBER Macro Annual 15, 339-390.

Obstfeld, M., 2007, International Risk Sharing, The Ohlin Lectures, Stockholm School of Economics.

Opazo, L., 2006, The Backus-Smith Puzzle: The Role of Expectations, Working Paper 395, Central Bank of Chile.

Ratto, R., W. Roeger and J. in’t Veld, 2008, Quest III: an Estimated DSGE Model of the Euro Area with Fiscal and Monetary Policy, Economic Papers 335, European Commission.

Santos Monteiro, P., 2008, Testing Full Consumption Insurance in the Frequency Domain, Working Paper, Warwick University.

Weil, P., 1990, Hand-To-Mouth Consumers and Asset Prices, European Economic Review 36, 575-583. 
Predicted moments generated by model and empirical statistics (US, G6)

Full risk

sharing model

Shocks to:

\begin{tabular}{c} 
HTM model \\
\hline Shocks to:
\end{tabular}

$\begin{array}{lll}\boldsymbol{Y}, \boldsymbol{I}, \boldsymbol{\lambda} & \boldsymbol{Y}, \boldsymbol{I} & \boldsymbol{Y}, \boldsymbol{\lambda}\end{array}$

(1)
(2)
(3)

$Y, I$

(4)

Data

(5)

(a) Model predictions: Baseline calibration

$\operatorname{Corr}\left(R E R, C_{H} / C_{F}\right)$

$\operatorname{Std}(\widehat{R E R})$ in \%

$\operatorname{Std}\left(\widehat{C}_{i}\right)$ in \%

$\operatorname{Std}\left(N X_{i} /\left(p_{i} Y_{i}\right)\right)$ in \%

$\operatorname{Corr}\left(C_{i}, Y_{i}\right)$

$\operatorname{Corr}\left(C_{H}, C_{F}\right)$
$-0.07 \quad-0.39$

2.69

0.96

0.13

0.63

0.40

2.94

0.91

0.65

$-0.79$

$-1.00$

0.24

1.74

8.25

0.91

1.06

2.15

0.06

0.29

0.57

0.71

0.99

0.54

0.19

(b) High HTM income share, $\Lambda=0.6$

$\operatorname{Corr}\left(\mathrm{RER}, \mathrm{C}_{\mathrm{H}} / \mathrm{C}_{\mathrm{F}}\right)$

0.63

$\operatorname{Std}(\widehat{R E R})$ in \%

6.04

0.40

$-0.24$

$-1.00$

0.24

$\operatorname{Std}\left(\widehat{C}_{i}\right)$ in \%

1.11

5.78

6.01

1.74

8.25

$\operatorname{Std}\left(N X_{i} /\left(p_{i} Y_{i}\right)\right)$ in \%

0.24

0.98

2.17

0.91

1.06

$\operatorname{Corr}\left(C_{i}, Y_{i}\right)$

0.65

0.23

0.16

0.06

0.29

$\operatorname{Corr}\left(C_{H}, C_{F}\right)$

0.04

0.72

0.97

0.57

0.71

0.33

0.64

0.54

0.19

(c) Low HTM income share, $\Lambda=0.25$

$\operatorname{Corr}\left(R E R, C_{H} / C_{F}\right) \quad-0.6$

$\operatorname{Std}(\widehat{R E R})$ in \%

$-0.61$

1.92

$-0.77 \quad-0.94$

$-1.00$

0.24

$\operatorname{Std}\left(\widehat{C}_{i}\right)$ in \%

$\begin{array}{lll}0.93 & 0.91 & 2.15\end{array}$

1.74

8.25

$\operatorname{Std}\left(N X_{i} /\left(p_{i} Y_{i}\right)\right)$ in \%

0.09

0.10

0.06

0.91

1.06

$\operatorname{Corr}\left(C_{i}, Y_{i}\right)$

0.60

0.61

0.99

0.06

0.29

$\operatorname{Corr}\left(C_{H}, C_{F}\right)$

0.49

0.56

0.68

0.57

0.71

0.54

0.19

(d) High substitution elasticity between domestic and foreign goods, $\phi=2$

$\begin{array}{lrrrrr}\operatorname{Corr}\left(R E R, C_{H} / C_{F}\right) & 0.12 & -0.14 & -0.71 & -1.00 & 0.24 \\ \operatorname{Std}(\widehat{R E R}) \text { in \% } & 1.72 & 1.88 & 2.60 & 1.32 & 8.25 \\ \operatorname{Std}\left(\widehat{C_{i}}\right) \text { in \% } & 0.96 & 0.90 & 2.10 & 0.87 & 1.06 \\ \operatorname{Std}\left(N X_{i} /\left(p_{i} Y_{i}\right)\right) \text { in \% } & 0.23 & 0.25 & 0.25 & 0.14 & 0.29 \\ \operatorname{Corr}\left(C_{i}, Y_{i}\right) & 0.65 & 0.68 & 0.98 & 0.58 & 0.71 \\ \operatorname{Corr}\left(C_{H}, C_{F}\right) & 0.40 & 0.59 & 0.75 & 0.71 & 0.19 \\ \text { (e) High risk aversion, } \sigma=5 & & & & & \\ \operatorname{Corr}\left(R E R, C_{H} / C_{F}\right) & 0.20 & -0.02 & -0.66 & -1.00 & 0.24 \\ \operatorname{Std}(\widehat{R E R}) \text { in \% } & 4.35 & 4.76 & 6.57 & 3.12 & 8.25 \\ \operatorname{Std}\left(\widehat{C_{i}}\right) \text { in \% } & 0.96 & 0.90 & 2.09 & 0.86 & 1.06 \\ \operatorname{Std}\left(N X_{i} /\left(p_{i} Y_{i}\right)\right) \text { in \% } & 0.17 & 0.18 & 0.16 & 0.09 & 0.29 \\ \operatorname{Corr}\left(C_{i}, Y_{i}\right) & 0.65 & 0.69 & 0.97 & 0.58 & 0.71 \\ \operatorname{Corr}\left(C_{H}, C_{F}\right) & 0.39 & 0.60 & 0.79 & 0.73 & 0.19\end{array}$


Table--ctd

Notes-Cols. (1)-(3) show predicted statistics generated by the model with hand-to-mouth (HTM) households. Col. (1): shocks to (Home and Foreign) output, investment and GDP shares received by HTM households; Col. (2): just output and investment shocks; Col. (3) just shocks to output and GDP shares received by HTM households.

Col. (4) shows predictions of model variant with full risk sharing (no HTM households, $\Lambda=0$ ), with output and investment shocks.

Col. (5) reports averages empirical statistics for the US and an aggregate of the remaining G7 countries ('G6'), based on annual data (1972-2003). Empirical statistics for the real exchange rate $(R E R)$, consumption $\left(C_{i}\right)$ and output $\left(Y_{i}\right)$ pertain to growth rates; empirical statistics for net exports $\left(N X_{i} /\left(p_{i} Y_{i}\right)\right)$ pertain to bilateral net export series (1980-2003) that were normalized by nominal domestic GDP and then first differenced. The empirical consumption measure is real purchases of non-durables and services; the real exchange rate is defined using non-durables and services deflators (exception: the German quantity and price series, used to construct G6 consumption and the G6 price index, pertain to total consumption). 